\title{
DPP-4 inhibition contributes to the prevention of hypoglycaemia through a GIP-glucagon counterregulatory axis in mice
}

\author{
Siri Malmgren • Bo Ahrén
}

Received: 2 October 2014 / Accepted: 19 January 2015 / Published online: 9 February 2015

(C) Springer-Verlag Berlin Heidelberg 2015

\begin{abstract}
Aims/hypothesis Glucose-lowering therapy with dipeptidyl peptidase-4 (DPP-4) inhibitors is associated with a low risk of hypoglycaemia. We hypothesise that DPP-4 inhibition prevents hypoglycaemia via increased glucagon counterregulation through the incretin hormone glucose-dependent insulinotropic polypeptide (GIP).

Methods Using a hyperinsulinaemic-hypoglycaemic clamp that targeted $2.5 \mathrm{mmol} / \mathrm{l}$ we examined the effects of the DPP4 inhibitor vildagliptin and GIP infusion on steady state glucose infusion rate (GIR) and glucagon counterregulation in mice. Following up on this, we performed a hyperinsulinaemichypoglycaemic clamp in mice carrying a genetic deletion of the GIP receptor $\left(\mathrm{GIPR}^{-/}\right.$mice) or the glucagon receptor $\left(\mathrm{GCGR}^{-/-}\right.$mice).

Results GIR was reduced by $89.0 \pm 3.1 \%\left(p=7.0 \times 10^{-6}\right)$ by vildagliptin and by $38.8 \pm 12.6 \%$ ( $p=0.040)$ by GIP in wildtype (wt) mice, whereas GIR was increased both in $\mathrm{GIPR}^{-/}$ (to $33.0 \pm 6.8$ from $14.0 \pm 2.9 \mu \mathrm{mol} \mathrm{kg}^{-1} \mathrm{~min}^{-1} ; p=0.017$ ) and in $\mathrm{GCGR}^{-/-}$mice (to $59.4 \pm 1.1$ from $16.5 \pm 2.4 \mu \mathrm{mol} \mathrm{kg}{ }^{-1}$ $\min ^{-1} ; p=8.2 \times 10^{-7}$ ) compared with wt. By contrast, neither vildagliptin nor GIP had any effect on GIR in $\mathrm{GCGR}^{-/-}$mice. Furthermore, vildagliptin increased intact GIP four- to eightfold during hypoglycaemia and the counterregulatory increase in glucagon levels during hypoglycaemia was augmented by vildagliptin (incremental AUC [iAUC] during clamp was $99.2 \pm 22.5$ vs $42.0 \pm 4.5 \mathrm{pmol} / 1 \times \min$ in controls; $p=0.039$ ) and GIP (iAUC of fold change during clamp was $372 \pm 81 \mathrm{vs}$ $161 \pm 40 \mathrm{FC} \times$ min with saline; $p=0.031$ ).

Conclusions/interpretation Based on these results we propose that DPP-4 inhibition protects from hypoglycaemia by
\end{abstract}

S. Malmgren $(\bowtie) \cdot B$. Ahrén

Department of Clinical Sciences, Lund, Medicine, Biomedical

Centre C11, Lund University, SE-221 84 Lund, Sweden

e-mail: siri.malmgren@med.lu.se augmenting glucagon counterregulation through a GIP-glucagon counterregulatory axis.

Keywords DPP-4 inhibitor · Entero-islet axis · Glucagon · Glucagon secretion · Glucose-dependent insulinotropic polypeptide $\cdot$ Hypoglycaemia $\cdot$ Hypoglycaemic clamp

\begin{tabular}{|c|c|}
\hline \multicolumn{2}{|c|}{ Abbreviations } \\
\hline DIRKO & Double incretin receptor knockout \\
\hline DPP-4 & Dipeptidyl peptidase-4 \\
\hline GCGR & Glucagon receptor \\
\hline GIP & Glucose-dependent insulinotropic polypeptide \\
\hline GIPR & GIP receptor \\
\hline GIR & Glucose infusion rate \\
\hline GLP-1 & Glucagon-like peptide-1 \\
\hline iAUC & Incremental AUC \\
\hline wt & Wild-type \\
\hline
\end{tabular}

\section{Introduction}

Glucose-lowering therapy in both type 1 and type 2 diabetes is commonly associated with hypoglycaemic events $[1,2]$. This is not only unpleasant and potentially dangerous but also lowers both adherence to therapy and quality of life, and is associated with long-term complications [3-6]. Therefore, it is important to develop glucose-lowering strategies that lack the risk of hypoglycaemia, such as those that support the physiological hypoglycaemic defence mechanisms.

Endogenous hypoglycaemic defence is based on a series of counterregulatory mechanisms. Initially, suppressed insulin secretion is followed, as blood glucose decreases further, by the release of counterregulatory factors aimed at stimulating liver glycogenolysis and subsequent liver glucose release to restore 
circulating glucose [7-9]. Glucagon is a key counterregulatory factor since it is released during hypoglycaemia and stimulates liver glucose release [9]. The importance of supporting this glucagon counterregulatory mechanism is underlined by the compromised glucagon response to hypoglycaemia that often exists in type 1 and type 2 diabetes [10-12].

Dipeptidyl peptidase-4 (DPP-4) inhibition is a glucoselowering strategy that carries a low risk of hypoglycaemia $[13,14]$, to which sustained glucagon counterregulation to hypoglycaemia may contribute, as recently suggested [15, 16]. In fact, we have previously shown that DPP-4 inhibition improves the responsiveness of the alpha cell to hypoglycaemia [16], resulting in stimulation of glucagon secretion during hypoglycaemia. Increased glucose sensitivity in alpha cells at low glucose with augmented glucagon counterregulation in hypoglycaemia might be achieved by the incretin hormone glucose-dependent insulinotropic polypeptide (GIP), as GIP has been shown to potentiate glucagon secretion at hypoglycaemic levels in healthy men [17]. Since DPP-4 inhibition prevents the inactivation of GIP and thereby raises the circulating level of active GIP, as has been reported in the mouse and in multiple other species [18-23], this incretin hormone may mediate protection from hypoglycaemia during DPP-4 inhibition. However, whether or not DPP-4 inhibition actually limits hypoglycaemia via a GIP-glucagon counterregulatory axis is still not known.

The aim of this study was, therefore, to investigate the concept that DDP-4 inhibition protects from hypoglycaemia and to elucidate the mechanisms. We thus explored the hyperinsulinaemic-hypoglycaemic clamp in mice treated with the DPP-4 inhibitor vildagliptin infused with GIP or genetically deleted for the GIP receptor (GIPR) or the glucagon receptor (GCGR). We hypothesised that increased levels of circulating active GIP by DPP-4 inhibition contribute to the low risk of hypoglycaemia by protecting against hypoglycaemia through stimulation of glucagon secretion.

\section{Methods}

Animal housing C57BL/6J mice were obtained from Taconic (Skensved, Denmark) and were housed on arrival in a room with a $12 \mathrm{~h}$ light-dark cycle at $22^{\circ}$. A standard research diet R34 (Lantmännen, Stockholm, Sweden) and water was provided ad libitum. All experimental procedures were performed in agreement with the Animal Ethics Committee in Lund, Sweden (Approval number 14 331-12:1).

Hyperinsulinaemic clamp Mice were anaesthetised using an intraperitoneal injection of midazolam $(18 \mathrm{mg} / \mathrm{kg}$ animal, Dormicum, Hoffman-La Roche, Basel, Switzerland) and fluanisone/fentanyl $(41 / 9 \mathrm{mg} / \mathrm{kg}$ animal respectively, Hypnorm, Janssen, Beerse, Belgium). Surgery and clamp experiments were performed as previously described [24] with the protocol modification of returning of erythrocytes as previously described [25]. Briefly, the right jugular vein and the left carotid artery were catheterised using catheters filled with heparinised saline $(100 \mathrm{U} / \mathrm{ml})$. The venous catheter was used for infusion while blood samples were obtained through the arterial catheter. The mice remained anaesthetised to reduce variations in the blood glucose concentrations due to stress. Following baseline sampling, synthetic human insulin (Actrapid, Novo Nordisk, Bagsvaerd, Denmark) was infused as a continuous infusion $\left(15 \mathrm{mU} \mathrm{kg} \mathrm{animal}{ }^{-1} \mathrm{~min}^{-1}\right)$ at a pace of $2 \mu \mathrm{l} / \mathrm{min}$ for $90 \mathrm{~min}$. Blood glucose in $\sim 5 \mu \mathrm{l}$ whole blood was determined every 10 min with an Accu-Chek Aviva blood glucose monitor (Hoffman-LaRoche) and the arterial catheter was flushed with heparinised saline $(100 \mathrm{U} / \mathrm{ml})$ following each sampling. A variable amount of glucose solution was infused to maintain blood glucose levels at $2.5 \mathrm{mmol} / \mathrm{l}$. A $10 \%$ glucose solution was used for all experiments except those in $\mathrm{GCGR}^{--}$mice where a $20 \%$ glucose solution was used due to the greater glucose requirements of this strain. Glucose requirement to maintain target glucose was represented by the glucose infusion rate (GIR) during the final $30 \mathrm{~min}$ of the steady state of the clamp.

Meal and drug administration For mice treated with vildagliptin $(10 \mathrm{mg} / \mathrm{kg}$ animal; Novartis, Basel, Switzerland), the drug was administered in a $60 / 20 / 20 \mathrm{E} \%$ glucose/protein/lipid mixed meal solution as previously described [26] as a $200 \mu$ l gavage $45 \mathrm{~min}$ prior to the clamp under isolfluorane inhalation.

GIP infusion When performing the clamp with GIP infusion the animals were first primed with $500 \mathrm{pmol} / \mathrm{kg}$ of porcine GIP (Bachem, Bubendorf, Switzerland) following sampling of the baseline time point. From this time point and for the duration of the experiment the animals were continuously infused with porcine GIP at a rate of $50 \mathrm{pmol} \mathrm{kg} \mathrm{animal}{ }^{-1} \mathrm{~min}^{-1}$, as previously used in rodents [27] through the jugular vein catheter.

Generation of knockout mice Generation of the GIPR ${ }^{-1}$ mice used in these experiments has been described previously [28]. In our hands, $\mathrm{GIPR}^{-/}$mice were generated on a C57BL/6J background by backcrossing of double incretin receptor knockout (DIRKO) mice [29] with C57BL/6J wild-type (wt) followed by F1 crossing. The generation of $\mathrm{GCGR}^{-/-}$mice used in these experiments has been described previously [30].

Hormone measurements Plasma glucagon was measured with sandwich immunoassay technique (ELISA, Mercodia, Uppsala, Sweden), using double monoclonal antibodies, according to the manufacturer's protocol. For this measurement, $25 \mu \mathrm{l}$ of plasma was collected at $0,30,60$ and $90 \mathrm{~min}$ and stored at $-20^{\circ}$ awaiting analysis. Samples were analysed 
together with duplicates of blanks and a ladder ranging from 1.49 to $127 \mathrm{pmol} / \mathrm{l}$. Plasma insulin was analysed with ELISA (Mercodia) using double monoclonal antibodies according to the manufacturer's protocol. Plasma intact GIP $\left(\mathrm{GIP}_{1-42}\right)$ was analysed with ELISA (Crystal Chem, Downers Grove, IL, USA) according to the manufacturer's protocol.

Statistical analysis All data are presented as mean \pm SEM and calculated and visualised using GraphPad Prism for windows, version 22 (La Jolla, CA, USA). Comparisons between groups were performed using a two-tailed Student's $t$ test or a two-way ANOVA with a Holm-Sidak's multiple comparison test post hoc. Comparisons within groups between time points were performed using repeated measure ANOVA, and the difference from 0 min was calculated post hoc using Holm-Sidak's multiple comparison test. The incremental AUC (iAUC) was calculated using the trapezoidal rule. Differences were considered statistically significant when $p<0.05$.

\section{Results}

DPP-4 inhibition increases active GIP and protects from hypoglycaemia We initially examined whether the DPP-4-inhibitor vildagliptin counteracts insulin-induced hypoglycaemia in anaesthetised female C57BL/6J mice. Vildagliptin- and placebo-treated mice were, therefore, subjected to a hyperinsulinaemic-hypoglycaemic clamp at $2.5 \mathrm{mmol} / \mathrm{l}$ of blood glucose (Fig. 1a) by infusing variable amounts of glucose together with the continuous insulin infusion (Fig. 1b). It was found that GIR was lowered by $89.0 \pm$ $3.1 \%$ in mice given vildagliptin compared with control mice $\left(3.9 \pm 1.1\right.$ vs $35.1 \pm 3.1 \mu \mathrm{mol} \mathrm{kg}{ }^{-1} \min ^{-1} ; p=7.0 \times 10^{-6}$ [Fig. 1c]). This result implies that DPP-4 inhibition strongly protects from insulin-induced hypoglycaemia.

To examine the dynamics of intact GIP during a hypoglycaemic clamp at $2.5 \mathrm{mmol} / \mathrm{l}$ following ingestion of a mixed meal with or without DPP-4 inhibitor vildagliptin, levels of intact GIP $\left(\mathrm{GIP}_{1-42}\right)$ were measured during the clamp. Meal ingestion increased plasma levels of intact GIP 45-fold in the group treated with vildagliptin compared with sixfold in control (data not shown). Levels of intact GIP during clamp showed no effect of insulin-induced hypoglycaemia on GIP dynamics in either group (Fig. 1d); however, there was a sevenfold increase in the level of intact GIP in the vildagliptin group compared with controls at the start of the clamp experiment $(413 \pm 34.9$ vs $56.8 \pm 6.3 \mathrm{pmol} / \mathrm{l} ; p=1.35 \times$ $10^{-5}$ [Fig. 1d]). Furthermore, the levels of intact GIP remained significantly higher (four- to eightfold; $p<0.01$ ) for the duration of the clamp.

Next, we measured glucagon levels during the clamp. Glucagon was significantly increased compared with baseline by insulin-induced hypoglycaemia in both groups during the clamp period (60 and $90 \mathrm{~min}$ [Fig. 1e]). In addition, we found a

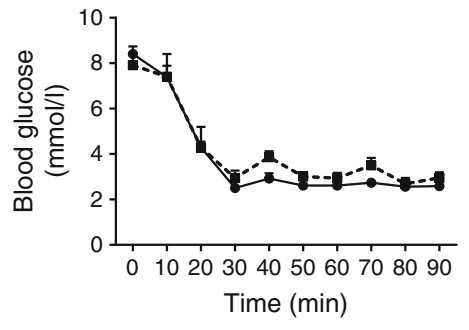

d

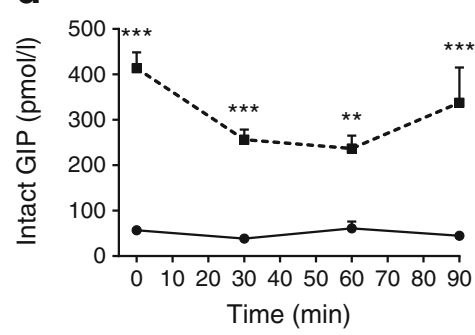

b

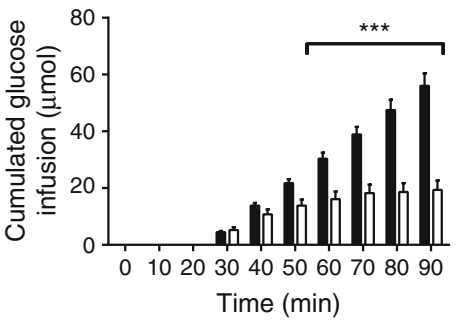

e

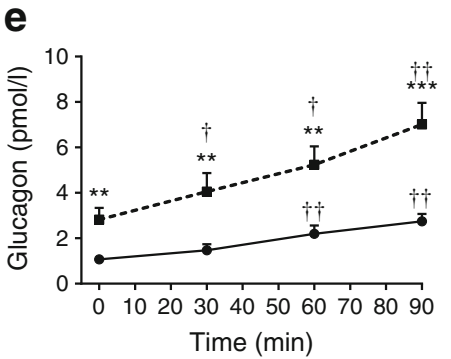

C
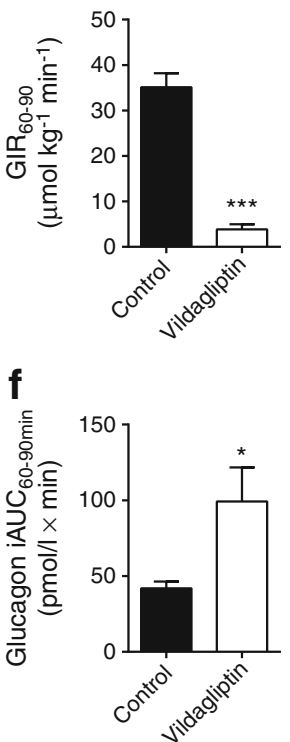

Fig. 1 (a) Blood glucose levels and (b) cumulated glucose infusion during a hyperinsulinaemic-hypoglycaemic clamp in female C57BL/6J mice treated with the DPP-4 inhibitor vildagliptin (squares/white bars) or saline control (circles/black bars). Steady state glucose is obtained during the last 30 min of the experiment. (c) Steady state GIR in controls (black bar) and animals treated with vildagliptin (white bar). (d) Intact GIP levels, (e) glucagon levels and (f) iAUC of glucagon levels during steady state glucose during a hyperinsulinaemic-hypoglycaemic clamp in female wt animals treated with the DPP-4 inhibitor vildagliptin (squares/white bar) or saline (circles/black bar). Data are mean $\pm \mathrm{SEM}, n=8$ for each group. $* p<0.05, * * p<0.01, * * * p<0.001$, compared with saline control; ${ }^{\dagger} p<0.05,{ }^{\dagger \dagger} p<0.01$ compared with 0 min for each group; brackets indicate the same level of significance for all time points 
that animals treated with vildagliptin had significantly higher glucagon levels during steady state at $60 \mathrm{~min}(5.2 \pm 0.8$ vs 2.2 $\pm 0.4 \mathrm{pmol} / \mathrm{l} ; p=0.004)$ and $90 \mathrm{~min}(7.0 \pm 0.9 \mathrm{vs} 2.7 \pm 0.3 \mathrm{pmol} / \mathrm{l}$; $p=0.0008$ [Fig. 1e]) after the start of the clamp. This resulted in a significantly higher iAUC during steady state in animals treated with vildagliptin compared with controls $(99.2 \pm 22.5$ vs $42.0 \pm 4.5 \mathrm{pmol} / 1 \times \min ; p=0.039$ [Fig. 1f]].

Blood glucose at $25 \mathrm{~min}$ after the gavage differed significantly between the group treated with vildagliptin and wt controls ( $7.3 \pm 0.7$ vs $9.3 \pm 0.3 \mathrm{mmol} / 1 ; p=0.019)$. To confirm that the treatment itself did not affect endogenous insulin release, which should be suppressed by hypoglycaemia, we measured insulin at baseline and during clamp and this did not differ between groups (Table 1).

Glucagon in hypoglycaemic counterregulation We examined the importance of glucagon for the glucose counterregulation to hypoglycaemia in mice by using male and female GCGR knockout mice $\left(\mathrm{GCGR}^{-/}\right)$and their wt controls, which were submitted to a hyperinsulinaemic-hypoglycaemic clamp at $2.5 \mathrm{mmol} / \mathrm{l}$ of blood glucose. GCGR ${ }^{-/-}$animals of both sexes had lower blood glucose before the experiment $(4.1 \pm 0.3 \mathrm{vs}$ $7.8 \pm 0.6 \mathrm{mmol} / \mathrm{l} ; p=0.0018$ in males; and $4.0 \pm 0.3$ vs $7.5 \pm$ $0.6 \mathrm{mmol} / \mathrm{l} ; p=0.0018$ in females [Fig. 2a, d]) but from minute 30 of the clamp and for the duration of the experiment the groups did not differ in blood glucose level. However, $\mathrm{GCGR}^{-/}$animals required a larger glucose infusion during the clamp to maintain blood glucose (Fig. 2b, e), such that they had a significantly higher GIR during the clamp (59.4 \pm 1.1 vs $16.5 \pm 2.4 \mu \mathrm{mol} \mathrm{kg}{ }^{-1} \mathrm{~min}^{-1} ; p=8.2 \times 10^{-7}$ in males; and $82.2 \pm 8.6$ vs $37.8 \pm 5.2 \mu \mathrm{mol} \mathrm{kg}{ }^{-1} \mathrm{~min}^{-1} ; p=0.0045$ in females [Fig. 2c, f]), showing impaired hypoglycaemic defence in these animals. This finding shows the importance of glucagon for glucose counterregulation in mice. There was no significant different between sexes in the GIR during clamp of $\mathrm{GCGR}^{-/}$ animals $(p>0.05)$.
To further explore whether or not the protective effect of vildagliptin on hypoglycaemia is glucagon dependent, female $\mathrm{GCGR}^{-/}$mice were subjected to a hypoglycaemic clamp after being given a mixed meal with or without vildagliptin (Fig. 3a). Despite the marked reduction in GIR by vildagliptin in wt animals (Fig. 1), its effects were ablated in the absence of the glucagon receptor (Fig. 3b, c) since GIR was not significantly affected by vildagliptin in $\mathrm{GCPR}^{-/-}$mice. Blood glucose at $25 \mathrm{~min}$ after the gavage did not differ significantly between $\mathrm{GCGR}^{-/-}$animals treated with vildagliptin and controls ( $4.2 \pm 0.6$ vs $4.5 \pm 0.4 \mathrm{mmol} / 1 ; p=0.645)$, and neither did insulin levels at baseline or during clamp (Table 1).

$G \mathrm{FR}^{-/}$mice are more vulnerable to hypoglycaemia Next, we explored whether or not the GIP-glucagon axis explains the protective action of DPP-4 inhibition on hypoglycaemia. The rationale for this approach was that GIP stimulates glucagon secretion at low glucose levels [17], that DPP-4 inhibition elevates levels of the active form of GIP [18-23] and that glucagon is a counterregulatory hormone [7, 9].

We thus explored the hyperinsulinaemic-hypoglycaemic clamp in GIPR ${ }^{-/}$mice. We found that blood glucose levels were significantly lower at baseline in male $\mathrm{GIPR}^{-/}$mice compared with their wt littermates $(6.3 \pm 0.3$ vs $7.8 \pm$ $0.4 \mathrm{mmol} / \mathrm{l} ; p=0.023$ [Fig. 4a]) but did not differ from minute 30 of the clamp and for the duration of the experiment. Nonetheless, GIPR ${ }^{-/-}$mice required more infused glucose to avoid dropping below $2.5 \mathrm{mmol} / 1$ glucose during the clamp (Fig. 4b) resulting in a significantly higher GIR during clamp compared with wt animals (33.0 \pm 6.8 vs $14.0 \pm 2.9 \mu \mathrm{mol} \mathrm{kg}^{-1}$ $\min ^{-1} ; p=0.017$ [Fig. 4c]). Hence, GIPR ${ }^{-/-}$mice are more sensitive to hypoglycaemia than their wt littermates.

GIP infusion protects from hypoglycaemia and augments glucagon secretion To further explore the protective mechanisms of a GIP-glucagon axis on hypoglycaemia, we co-
Table 1 Insulin level (pmol/l) measured during clamp experiment with vildagliptin and GIP infusion

\begin{tabular}{|c|c|c|c|c|c|}
\hline Experiment & Figure & $n$ & Groups & $0 \min$ & $90 \mathrm{~min}$ \\
\hline \multirow[t]{3}{*}{ wt \pm vildagliptin } & 1 & 8 & Control & $414 \pm 43$ & $7,238 \pm 516$ \\
\hline & & & Vildagliptin & $561 \pm 130$ & $7,852 \pm 835$ \\
\hline & & & $p$ value & 0.31 & 0.54 \\
\hline \multirow[t]{3}{*}{$\mathrm{GCGR}^{-/} \pm$vildagliptin } & 3 & 5 & Control & $51 \pm 15$ & $3,217 \pm 875$ \\
\hline & & & Vildagliptin & $136 \pm 104$ & $6,136 \pm 2,128$ \\
\hline & & & $p$ value & 0.48 & 0.27 \\
\hline \multirow[t]{3}{*}{ wt \pm GIP infusion } & 5 & 10 & Saline & $271 \pm 61$ & $9,766 \pm 1,490$ \\
\hline & & & GIP & $438 \pm 71$ & $9,809 \pm 1,654$ \\
\hline & & & $p$ value & 0.090 & 0.98 \\
\hline \multirow[t]{3}{*}{$\mathrm{GCGR}^{-/-} \pm \mathrm{GIP}$ infusion } & 6 & 4 & Saline & $32 \pm 8$ & $4,755 \pm 1,157$ \\
\hline & & & GIP & $48 \pm 10$ & $4,770 \pm 504$ \\
\hline & & & $p$ value & 0.27 & 0.99 \\
\hline
\end{tabular}

Data are mean \pm SEM 
Fig. 2 (a, d) Blood glucose levels and $(\mathbf{b}, \mathbf{e})$ cumulated glucose infusion during a hyperinsulinaemichypoglycaemic clamp in (a-c) male and (d-f) female $\mathrm{GCGR}^{-/-}$ mice (squares/white bars) and matched wt controls (circles/black bars). Steady state glucose was obtained during the last $30 \mathrm{~min}$ of the experiment. (c, f) Steady state GIR in wt (black bar) or GCGR ${ }^{-/-}$ (white bar) animals. Data are mean $\pm \mathrm{SEM}, n=4$ for each group, ${ }^{*} p<0.05,{ }^{* *} p<0.01, * * * p<0.001$ compared with wt; brackets indicate the same level of significance for all time points
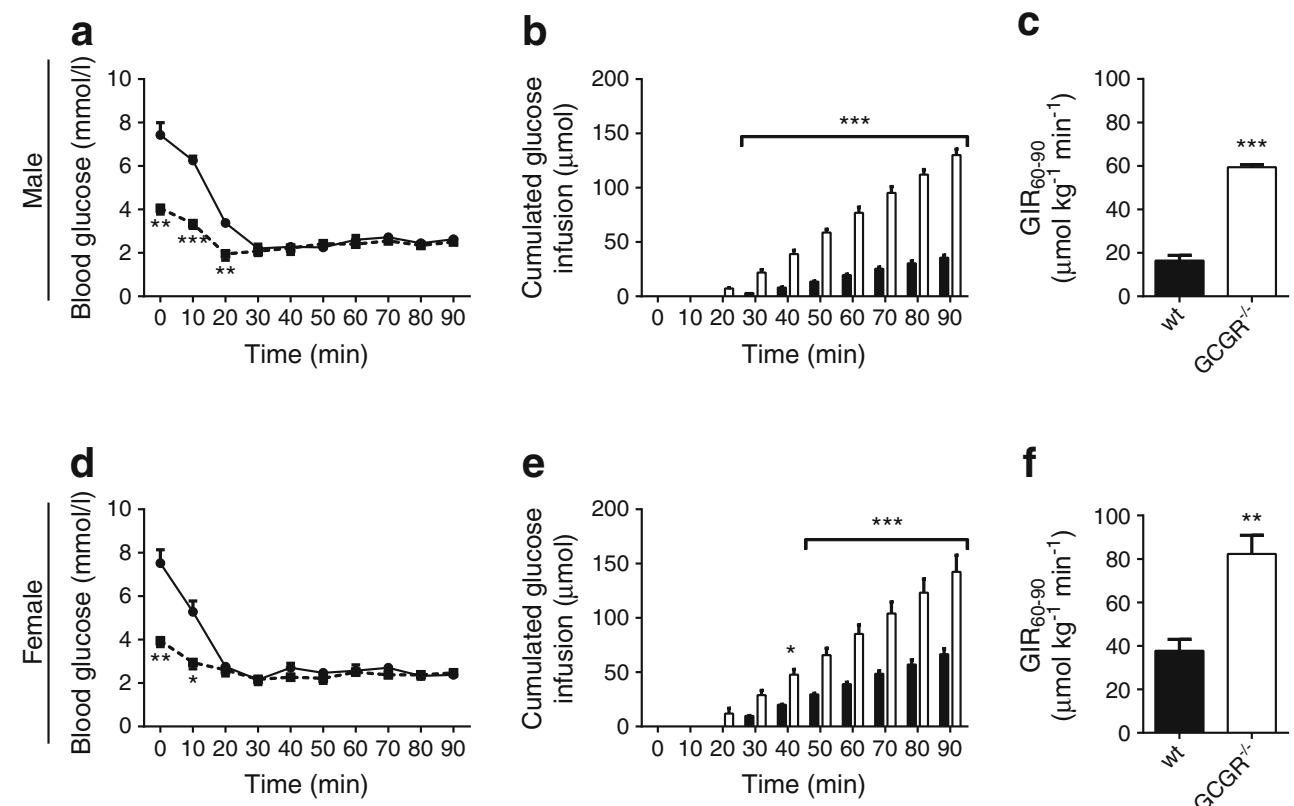

f

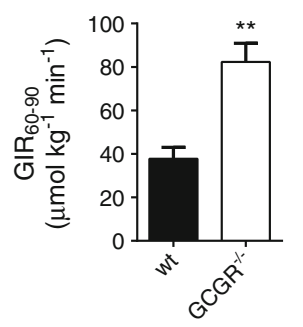

infused animals with $50 \mathrm{pmol} \mathrm{kg}{ }^{-1} \mathrm{~min}^{-1}$ of GIP or saline during the hypoglycaemic clamp (Fig. 5a). This resulted in a higher glucose requirement in animals infused with saline than GIP (Fig. 5b), which was reflected by a significantly higher GIR during clamp in saline-infused animals compared with GIP infused animals ( $38.2 \pm 4.7 \mathrm{vs} 23.4 \pm 4.8 \mu \mathrm{mol} \mathrm{kg}^{-1} \mathrm{~min}^{-1}$; $p=0.040$ [Fig. 5c]); GIP thus reduced GIR by $38.8 \pm 12.6 \%$ compared with saline. This effect on GIR by GIP was similar to that of vildagliptin but did not fully match the amount of glucose infused in that vildagliptin was associated with a significantly higher reduction in GIR $(89.0 \pm 3.1 \%$ compared with GIP infusion; $p=0.0030$ ).

Having established that GIP may contribute to the protective effect of DPP-4 inhibition on hypoglycaemia we explored whether or not this could be mediated by sustained glucagon counterregulation. We, therefore, measured glucagon levels at 0, 30,60 and 90 min of the clamp in animals infused with GIP. Plasma glucagon levels measured during the clamp in control animals vs animals infused with GIP were $4.1 \pm 1.4$ vs $8.6 \pm$ $3.0 \mathrm{pmol} / 1(p=0.197)$ and $6.1 \pm 2.0 \mathrm{vs} 12.0 \pm 4.3 \mathrm{pmol} / 1$ $(p=0.232)$ at 60 and $90 \mathrm{~min}$, respectively (Fig. $5 \mathrm{~d}$ ). This trend of higher glucagon levels by GIP infusion during hypoglycaemia did not reach significance. However, the glucagon response, expressed as fold change over $0 \mathrm{~min}$, was already significantly increased from baseline in both saline and GIP infused animals at $30 \mathrm{~min}(p=0.03$ and $p=0.01$, respectively), and was higher still at 60 and $90 \mathrm{~min}$ in both groups $(p<0.05$ and $p<0.01$, respectively compared with $0 \mathrm{~min}$ ). The glucagon response as fold change in glucagon over baseline differed significantly between groups at $60 \min (10.7 \pm 2.0$ in GIP vs $5.2 \pm 1.1$ with saline; $p=0.026$ [Fig. 5e]) and there was a strong tendency towards a difference at $90 \mathrm{~min}(16.1 \pm 3.8$ in GIP vs $7.6 \pm 1.7$ with saline; $p=0.055)$. This resulted in a significantly higher iAUC of fold change during clamp in animals infused with GIP compared with saline-infused wt animals $(372 \pm 81$ vs $161 \pm 40 \mathrm{FC} \times$ min;

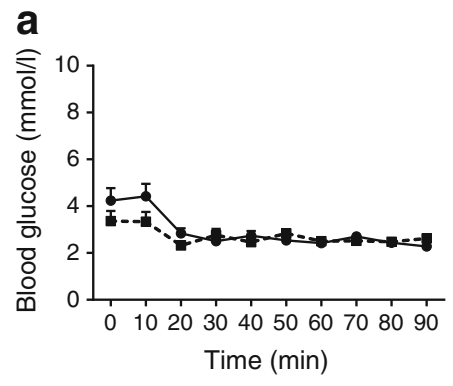

Fig. 3 (a) Blood glucose levels and (b) cumulated glucose infusion during a hyperinsulinaemic-hypoglycaemic clamp in female $\mathrm{GCGR}^{-/}$mice treated with the DPP-4 inhibitor vildagliptin (squares/white bars) or saline control (circles/black bars). Steady state glucose was obtained during the
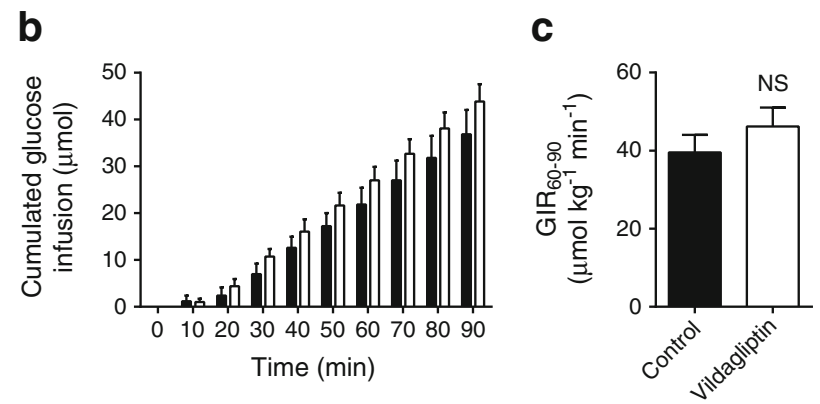

last $30 \mathrm{~min}$ of the experiment. (c) Steady state GIR in controls (black bar) and animals treated with vildagliptin (white bar). Data are mean $\pm \mathrm{SEM}$, $n=5$ 
a

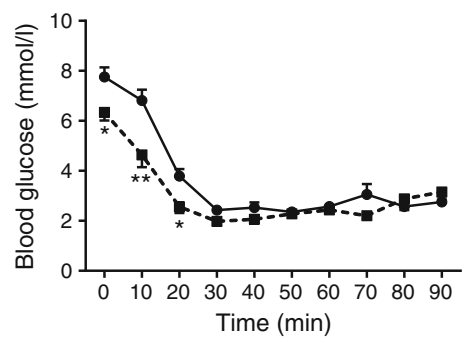

b

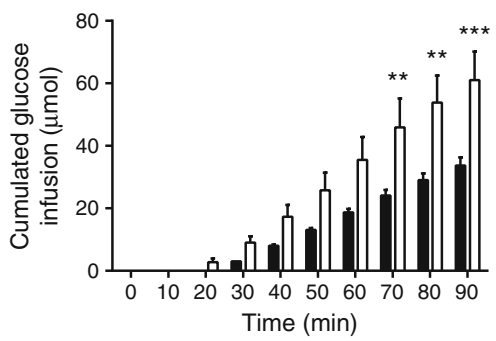

C

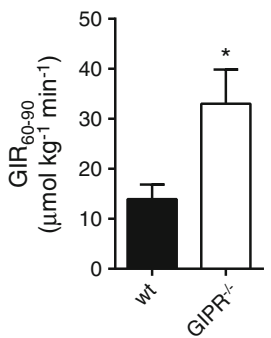

Fig. 4 (a) Blood glucose levels and (b) cumulated glucose infusion during a hyperinsulinaemic-hypoglycaemic clamp in male $\mathrm{GIPR}^{-/}$mice (squares/white bars) and matched wt controls (circles/black bars). Steady state glucose was obtained during the last $30 \mathrm{~min}$ of the experiment. (c)

$p=0.031$ [Fig. 5f]). Insulin levels at baseline and during clamp were not affected by GIP infusion and did not differ between groups (Table 1).

GIP infusion protection from hypoglycaemia is absent in $G C G R^{-/}$mice To further highlight the importance of glucagon in the protective mechanism of GIP on insulin-induced hypoglycaemia, $\mathrm{GCGR}^{-/}$mice were infused with GIP during a hyperinsulinaemic-hypoglycaemic clamp at $2.5 \mathrm{mmol} / \mathrm{l}$ of blood glucose (Fig. 6a). As previously shown, $\mathrm{GCGR}^{-/-}$mice needed greater glucose infusion than wt animals (Fig. 2) but in the $\mathrm{GCGR}^{-/}$animals, there was no difference in glucose infusion requirements between those infused with saline and GIP (Fig. 6b). This resulted in similar levels of GIR in both
Steady state GIR in wt animals (black bar) or GIPR ${ }^{-/}$animals (white bar). Data are mean \pm SEM, $n=5,{ }^{*} p<0.05,{ }^{* *} p<0.01,{ }^{* * *} p<0.001 \mathrm{com}-$ pared with wt

groups (Fig. 6c). Hence, GCGR deletion removes the protective effect of GIP on hypoglycaemia. Insulin levels at baseline and during clamp did not differ between groups (Table 1).

\section{Discussion}

In this study, we examined the mechanisms of the protective effect of DPP-4 inhibition on insulin-induced hypoglycaemia in mouse models. We found that the DPP-4 inhibitor vildagliptin markedly reduced the glucose requirement to maintain blood glucose at a targeted hypoglycaemic value ( $2.5 \mathrm{mmol} / \mathrm{l})$ during a hyperinsulinaemic-hypoglycaemic a

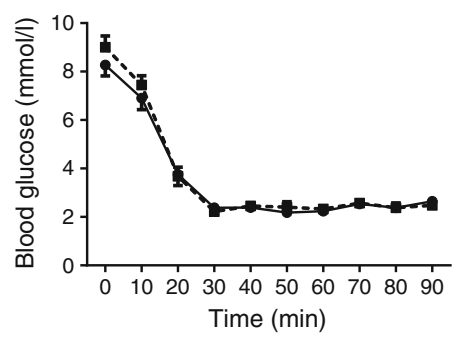

d

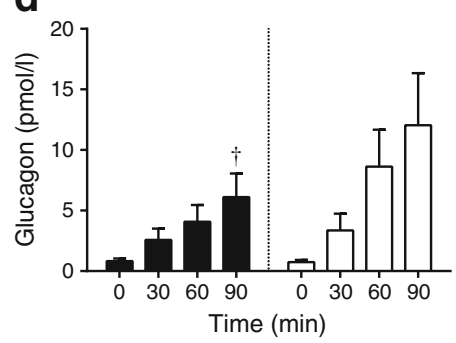

b

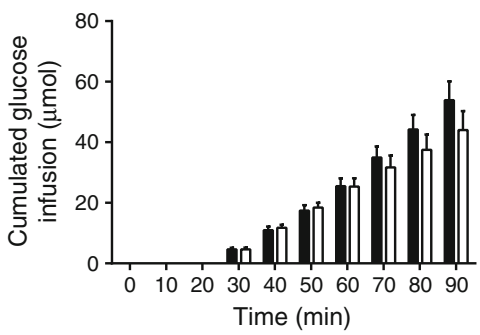

e

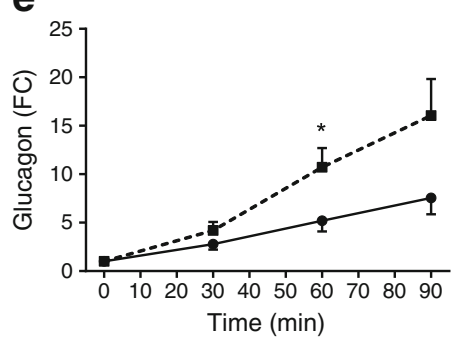

C

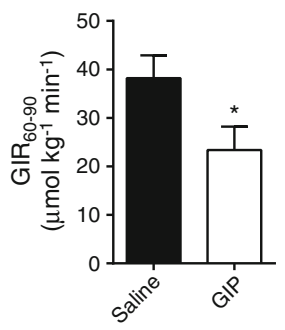

f

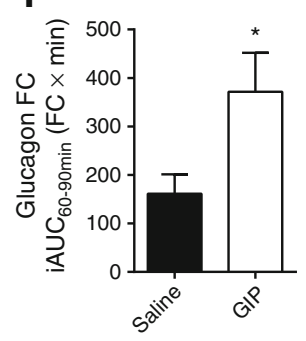

Fig. 5 (a) Blood glucose levels and (b) cumulated glucose infusion during a hyperinsulinaemic-hypoglycaemic clamp in female wt animals with GIP infusion (squares/white bars) or saline (circles/black bars). Steady state glucose was obtained during the last $30 \mathrm{~min}$ of the experiment. (c) Steady state GIR with GIP infusion (white bar) or saline (black bar). (d) Glucagon levels and (e) fold change (FC) increase in glucagon during a hyperinsulinaemic-hypoglycaemic clamp in female wt animals with GIP infusion (squares/white bars) or saline (circles/black bars). (f) iAUC in fold change in glucagon levels with GIP infusion (white bar) or saline (black bar) during steady state glucose. Data are mean \pm SEM, $n=10$, ${ }^{*} p<0.05$ compared with saline control; ${ }^{\dagger} p<0.05$ compared with 0 min for each group 


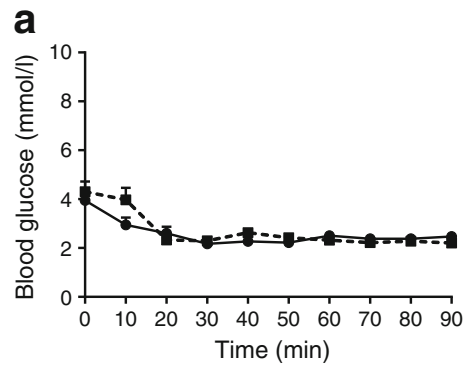

b

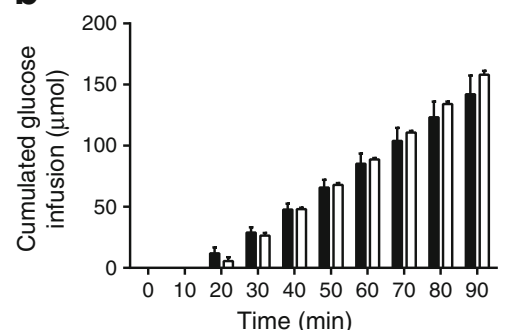

C

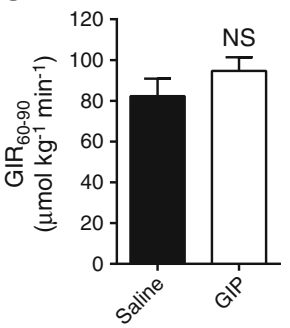

Fig. 6 (a) Blood glucose levels and (b) cumulated glucose infusion during a hyperinsulinaemic-hypoglycaemic clamp in female $\mathrm{GCGR}^{-/}$mice with GIP infusion (squares/white bars) or saline (circles/black bars).
Steady state glucose was obtained during the last $30 \mathrm{~min}$ of the experiment. (c) Steady state GIR with GIP infusion (white bar) or saline (black bar). Data are mean \pm SEM, $n=4$ clamp, suggesting a direct, protective effect of DPP-4 inhibition from insulin-induced hypoglycaemia. This finding is in agreement with the hypothesis that DPP-4 inhibition supports the endogenous hypoglycaemic defence as previous studies have shown for vildagliptin given to drug-naive patients [31] or added to insulin therapy in people with type 2 diabetes [32].

We also showed that the intact bioactive form of GIP, GIP ${ }_{1-}$ 42 , was significantly increased in the vildagliptin-treated group during clamp, which confirms the findings of a recent human study [21], but that insulin-induced hypoglycaemia in itself had no effect on intact GIP dynamics in either group. When further examining the nature of the protective effect of this DPP-4 inhibitor, we focused on glucagon since it was increased during clamp after vildagliptin-treatment and since it is a major protective mechanism in the endogenous hypoglycaemic defence [7, 9]. In addition, the importance of glucagon counterregulation is highlighted by the fact that it is disrupted in both type 1 and type 2 diabetes [10-12]. Therefore, as expected, $\mathrm{GCGR}^{-/-}$mice lacking the glucagon receptor demanded significantly more glucose to maintain steady state hypoglycaemia, as reflected by a higher GIR in these animals. We found that administration of vildagliptin to $\mathrm{GCGR}^{-/}$mice did not affect the high GIR, thus the protective effect of vildagliptin on hypoglycaemia was ablated by the genetic deletion of the glucagon receptor. The GIR during hypoglycaemia in $\mathrm{GCGR}^{-1}$ animals also remained high during exogenous infusion of GIP, whereas in wt animals GIP infusion protected from insulin-induced hypoglycaemia and this was accompanied by an increased glucagon response in a time-dependent manner. From these results we conclude that both vildagliptin and GIP infusion protect from hypoglycaemia by a glucagon-mediated mechanism. This may suggest that vildagliptin protects from hypoglycaemia by a GIP-glucagon counterregulatory axis, possibly by improving hypoglycaemic responsiveness in the alpha cells through GIP. This finding is in agreement with the our previously presented results that DPP-4 inhibition improves glucose homeostasis primarily by restoring glucose sensitivity in islet cells [33, 34], as well as the findings of a study in healthy humans where GIP infusion increased hyperglycaemic glucagon counterregulation in a time- and glucosedependent manner [17]. The decreased GIR seen with GIP infusion might reflect increased hepatic glucose production as a result of an accentuated glucagon response and suggests an operative GIP-glucagon axis for protection of hypoglycaemia.

To explore the role of GIP further, we examined GIPR ${ }^{-/}$ mice. These animals display a rather modest phenotype with normal fasting glucose and only mild glucose intolerance in response to an oral glucose challenge [28]. Furthermore, they do not differ significantly from wt animals in insulin sensitivity or plasma insulin levels [35]. However, the $\mathrm{GIPR}^{-/-}$mice required a much higher glucose infusion to maintain the target $2.5 \mathrm{mmol} / \mathrm{l}$ during the hypoglycaemic clamp than control mice, which indeed supports the suggestion that a main function of GIP is to be protective against hypoglycaemia.

Alterations in glucagon clearance could theoretically contribute to a counterregulatory response since nutritional state has been shown to affect glucagon clearance in mice [36]; however, this seems not to be directly affected by low blood glucose during hyperinsulinaemic clamp [37]. However, we cannot exclude a contribution by change in glucagon clearance to the counterregulatory response to hypoglycaemia, and this deserves further study.

DPP-4 inhibition also increases the active circulating levels of another incretin hormone, glucagon-like peptide-1 (GLP-1) [33], which could theoretically affect the hypoglycaemic glucagon response. However, since two human studies [38, 39] have shown that GLP-1 infusion during hypoglycaemia does not potentiate the glucagon response to hypoglycaemia, and since the GLP-1 receptor agonists liraglutide and albiglutide do not affect glucagon counterregulation [39, 40], GLP-1 does not appear to be the mediator of the enhanced counterregulation seen with DPP-4 inhibition. Nevertheless, since there is a quantitative difference in GIR to maintain target glucose during hypoglycaemia between vildagliptin and GIP infusion, and in light of the somewhat contradictory result of one study showing that the GLP-1 receptor agonist exenatide slightly increased glucagon secretion in hypoglycaemia [41], we cannot exclude protective effects 
besides the GIP-glucagon axis of DPP-4 inhibition using vildagliptin by other DPP-4 substrates, such a GLP-1; this would need to be explored in further studies.

In conclusion, we have shown that the DPP-4 inhibitor vildagliptin protects mice from insulin-induced hypoglycaemia through a GIP-glucagon counterregulatory axis. Using animals carrying a null-allele for the receptor of GIP or glucagon, we have shown that the lack of receptormediated effect of either hormone attenuates the endogenous hypoglycaemic defence. In addition, we have shown that infusion of GIP directly protects against insulin-induced hypoglycaemia in a GCGR-dependent manner and that this protection is accompanied by increased glucagon secretion in wt mice. Based on these findings, we suggest that increased levels of GIP during treatment with DPP-4 inhibition enhance the glucagon counterregulatory response and that strengthening this GIP-glucagon axis contributes to the low risk of hypoglycaemia associated with DPP-4 inhibitors.

Acknowledgements The authors would like to thank K. Andersson of Lund University, Lund, Sweden, for her experimental expertise. Furthermore, we extend our gratitude to Y. Yamada and Y. Seino of Kyoto University, Kyoto, Japan, for providing the DIRKO mice, to Novo Nordisk for providing the $\mathrm{GCGR}^{-/-}$mice and to Novartis Pharmaceuticals for providing vildagliptin.

Funding This study was supported by grants from Kungl. Fysiografiska Sällskapet i Lund, the Swedish Medical Research Council, Region Skåne and Lund University.

Duality of interest BA is a member of Novartis' speaker's bureau and has received research grants from Novartis. The remaining author declares that there is no duality of interest associated with their contribution to this manuscript.

Contribution statement SM designed the study, acquired, analysed and interpreted data and drafted and wrote the manuscript and the approved final version of manuscript. BA designed the study, analysed and interpreted data, wrote the manuscript and approved the final version of manuscript. BA is the guarantor of this work and, as such, had full access to all the data in the study and takes responsibility for the integrity of the data and the accuracy of the data analysis.

\section{References}

1. The Diabetes Control and Complications Trial Research Group (1993) The effect of intensive treatment of diabetes on the development and progression of long-term complications in insulindependent diabetes mellitus. N Engl J Med 329:977-986

2. The Diabetes Control and Complications Trial Research Group (1997) Hypoglycemia in the Diabetes Control and Complications Trial. Diabetes 46:271-286

3. Zhao YN, Campbell CR, Fonseca V, Shi LZ (2012) Impact of hypoglycemia associated with antihyperglycemic medications on vascular risks in veterans with type 2 diabetes. Diabetes Care 35:1126-1132

4. Ahren B (2013) Avoiding hypoglycemia: a key to success for glucose-lowering therapy in type 2 diabetes. Vasc Health Risk Manag 9:155-163
5. Barendse S, Singh H, Frier BM, Speight J (2012) The impact of hypoglycaemia on quality of life and related patient-reported outcomes in type 2 diabetes: a narrative review. Diabet Med 29:293-302

6. Zoungas S, Patel A, Chalmers J et al (2010) Severe hypoglycemia and risks of vascular events and death. N Engl J Med 363:1410-1418

7. Schwartz NS, Clutter WE, Shah SD, Cryer PE (1987) Glycemic thresholds for activation of glucose counterregulatory systems are higher than the threshold for symptoms. J Clin Invest 79:777-781

8. Mitrakou A, Ryan C, Veneman T et al (1991) Hierarchy of glycemic thresholds for counterregulatory hormone secretion, symptoms, and cerebral dysfunction. Am J Physiol 260:E67-E74

9. Unger RH, Orci L (1977) The role of glucagon in the endogenous hyperglycemia of diabetes mellitus. Annu Rev Med 28:119-130

10. Bolli G, de Feo P, Compagnucci P et al (1983) Abnormal glucose counterregulation in insulin-dependent diabetes mellitus. Interaction of anti-insulin antibodies and impaired glucagon and epinephrine secretion. Diabetes 32:134-141

11. Korzon-Burakowska A, Hopkins D, Matyka K et al (1998) Effects of glycemic control on protective responses against hypoglycemia in type 2 diabetes. Diabetes Care 21:283-290

12. Spyer G, Hattersley AT, MacDonald IA, Amiel S, MacLeod KM (2000) Hypoglycaemic counter-regulation at normal blood glucose concentrations in patients with well controlled type- 2 diabetes. Lancet 356:1970-1974

13. Kothny W, Foley J, Kozlovski P, Shao Q, Gallwitz B, Lukashevich V (2013) Improved glycaemic control with vildagliptin added to insulin, with or without metformin, in patients with type 2 diabetes mellitus. Diabetes Obes Metab 15:252-257

14. Kozlovski P, Foley J, Shao Q, Lukashevich V, Kothny W (2013) Vildagliptin-insulin combination improves glycemic control in Asians with type 2 diabetes. World J Diabetes 4:151-156

15. Farngren J, Persson M, Schweizer A, Foley JE, Ahren B (2012) Vildagliptin reduces glucagon during hyperglycemia and sustains glucagon counterregulation during hypoglycemia in type 1 diabetes. J Clin Endocrinol Metab 97:3799-3806

16. Ahren B, Schweizer A, Dejager S et al (2009) Vildagliptin enhances islet responsiveness to both hyper- and hypoglycemia in patients with type 2 diabetes. J Clin Endocrinol Metab 94:1236-1243

17. Christensen M, Vedtofte L, Holst JJ, Vilsboll T, Knop FK (2011) Glucose-dependent insulinotropic polypeptide: a bifunctional glucose-dependent regulator of glucagon and insulin secretion in humans. Diabetes 60:3103-3109

18. Deacon CF, Danielsen P, Klarskov L, Olesen M, Holst JJ (2001) Dipeptidyl peptidase IV inhibition reduces the degradation and clearance of GIP and potentiates its insulinotropic and antihyperglycemic effects in anesthetized pigs. Diabetes 50:1588-1597

19. Deacon CF, Wamberg S, Bie P, Hughes TE, Holst JJ (2002) Preservation of active incretin hormones by inhibition of dipeptidyl peptidase IV suppresses meal-induced incretin secretion in dogs. J Endocrinol 172:355-362

20. Mari A, Sallas WM, He YL et al (2005) Vildagliptin, a dipeptidyl peptidase-IV inhibitor, improves model-assessed beta-cell function in patients with type 2 diabetes. J Clin Endocrinol Metab 90:4888-4894

21. Farngren J, Persson M, Schweizer A, Foley JE, Ahren B (2014) Glucagon dynamics during hypoglycaemia and food-re-challenge following treatment with vildagliptin in insulin-treated patients with type 2 diabetes. Diabetes Obes Metab 16:812-818

22. Herman GA, Bergman A, Stevens C et al (2006) Effect of single oral doses of sitagliptin, a dipeptidyl peptidase- 4 inhibitor, on incretin and plasma glucose levels after an oral glucose tolerance test in patients with type 2 diabetes. J Clin Endocrinol Metab 91:4612-4619

23. Waget A, Cabou C, Masseboeuf M et al (2011) Physiological and pharmacological mechanisms through which the DPP-4 inhibitor sitagliptin regulates glycemia in mice. Endocrinology 152:3018-3029 
24. Pacini G, Thomaseth K, Ahren B (2001) Contribution to glucose tolerance of insulin-independent vs. insulin-dependent mechanisms in mice. Am J Physiol Endocrinol Metab 281:E693-E703

25. Alonso LC, Yokoe T, Zhang PL et al (2007) Glucose infusion in mice - a new model to induce beta-cell replication. Diabetes 56:1792-1801

26. Ahlkvist L, Vikman J, Pacini G, Ahren B (2012) Synergism by individual macronutrients explains the marked early GLP-1 and islet hormone responses to mixed meal challenge in mice. Regul Pept 178:29-35

27. Ravn P, Madhurantakam C, Kunze S et al (2013) Structural and pharmacological characterization of novel potent and selective monoclonal antibody antagonists of glucose-dependent insulinotropic polypeptide receptor. J Biol Chem 288:19760-19772

28. Miyawaki K, Yamada Y, Yano H et al (1999) Glucose intolerance caused by a defect in the entero-insular axis: a study in gastric inhibitory polypeptide receptor knockout mice. Proc Natl Acad Sci U S A 96:14843-14847

29. Hansotia T, Baggio LL, Delmeire D et al (2004) Double incretin receptor knockout (DIRKO) mice reveal an essential role for the enteroinsular axis in transducing the glucoregulatory actions of DPP-IV inhibitors. Diabetes 53:1326-1335

30. Gelling RW, Du XQ, Dichmann DS et al (2003) Lower blood glucose, hyperglucagonemia, and pancreatic alpha cell hyperplasia in glucagon receptor knockout mice. Proc Natl Acad Sci U S A 100:1438-1443

31. Pratley RE, Rosenstock J, Pi-Sunyer FX et al (2007) Management of type 2 diabetes in treatment-naive elderly patients: benefits and risks of vildagliptin monotherapy. Diabetes Care 30:3017-3022

32. Fonseca V, Schweizer A, Albrecht D, Baron MA, Chang I, Dejager S (2007) Addition of vildagliptin to insulin improves glycaemic control in type 2 diabetes. Diabetologia 50:1148-1155

33. Ahren B, Landin-Olsson M, Jansson PA, Svensson M, Holmes D, Schweizer A (2004) Inhibition of dipeptidyl peptidase-4 reduces glycemia, sustains insulin levels, and reduces glucagon levels in type 2 diabetes. J Clin Endocrinol Metab 89:2078-2084

34. Ahren B, Schweizer A, Dejager S, Villhauer EB, Dunning BE, Foley JE (2011) Mechanisms of action of the dipeptidyl peptidase-4 inhibitor vildagliptin in humans. Diabetes Obes Metab 13:775-783

35. Pamir N, Lynn FC, Buchan AMJ et al (2003) Glucose-dependent insulinotropic polypeptide receptor null mice exhibit compensatory changes in the enteroinsular axis. Am J Physiol Endocrinol Metab 284:E931-E939

36. Zhou A, Pacini G, Ahren B, D'Argenio DZ (2014) Glucagon clearance is regulated by nutritional state: evidence from experimental studies in mice. Diabetologia 57:801-808

37. Herold KC, Jaspan JB (1986) Hepatic glucagon clearance during insulin induced hypoglycemia. Horm Metab Res 18:431-435

38. Nauck MA, Heimesaat MM, Behle K et al (2002) Effects of glucagon-like peptide 1 on counterregulatory hormone responses, cognitive functions, and insulin secretion during hyperinsulinemic, stepped hypoglycemic clamp experiments in healthy volunteers. J Clin Endocrinol Metab 87:1239-1246

39. Christensen M, Calanna S, Sparre-Ulrich AH et al (2015) Glucosedependent insulinotropic polypeptide augments glucagon responses to hypoglycemia in type 1 diabetes. Diabetes 64:72-78

40. Hompesch M, Jones-Leone A, Carr MC et al (2015) Albiglutide does not impair the counter-regulatory hormone response to hypoglycaemia: a randomized, double-blind, placebo-controlled, stepped glucose clamp study in subjects with type 2 diabetes mellitus. Diabetes Obes Metab 17:82-90

41. Degn KB, Brock B, Juhl CB et al (2004) Effect of intravenous infusion of exenatide (synthetic exendin-4) on glucose-dependent insulin secretion and counterregulation during hypoglycemia. Diabetes 53:2397-2403 